Research Paper

\title{
Protective Effect of Thymoquinone against Cyclophosphamide-Induced Hemorrhagic Cystitis through Inhibiting DNA Damage and Upregulation of Nrf2 Expression
}

\author{
Prashant R. Gore1,\#, Chaitali P. Prajapati1,\#, Umesh B. Mahajan¹,\#, Sameer N. Goyal1, Sateesh Belemkar², \\ Shreesh Ojha ${ }^{3, \square}$, Chandragouda R. Patil $1, \square$ \\ 1. Department of Pharmacology, R. C. Patel Institute of Pharmaceutical Education and Research, Shirpur, District-Dhule, Maharashtra, 425405, India \\ 2. School of Pharmacy and Technology Management, SVKM's NMIMS, MPTP, Shirpur, District- Dhule, Maharashtra, 425405, India \\ 3. Department of Pharmacology and Therapeutics, College of Medicine and Health Sciences, United Arab Emirates, University, Al Ain, Abu Dhabi 17666, \\ United Arab Emirates. \\ \# These authors contributed equally to this work
}

$\triangle$ Corresponding authors: Dr. Chandragouda R. Patil1 and Dr. Shreesh Ojha2. ${ }^{1}$ Department of Pharmacology, R. C. Patel Institute of Pharmaceutical Education and Research, Shirpur, District-Dhule, Maharashtra, 425405, India, Phone: +91-2563-251808, Fax: +91-2563-255189, E- mail: xplore.remedies@gmail.com (C. R. Patil). ${ }^{2}$ Department of Pharmacology and Therapeutics, College of Medicine and Health Sciences, United Arab Emirates, University, PO Box: 17666, Al Ain, Abu Dhabi, United Arab Emirates, Phone: 00971-3-7137524; Fax: 00971-3-7672033, E-mail: shreeshojha@uaeu.ac.ae (S. Ojha).

() Ivyspring International Publisher. Reproduction is permitted for personal, noncommercial use, provided that the article is in whole, unmodified, and properly cited. See http://ivyspring.com/terms for terms and conditions.

Received: 2016.04.08; Accepted: 2016.05.06; Published: 2016.06.07

\begin{abstract}
Cyclophosphamide (CYP) induced hemorrhagic cystitis is a dose-limiting side effect involving increased oxidative stress, inflammatory cytokines and suppressed activity of nuclear factor related erythroid 2-related factor ( $\mathrm{Nr} 2$ ). Thymoquinone (TQ), an active constituent of Nigella sativa seeds, is reported to increase the expression of Nrf2, exert antioxidant action, and anti-inflammatory effects in the experimental animals. The present study was designed to explore the effects of TQ on CYP-induced hemorrhagic cystitis in Balb/c mice. Cystitis was induced by a single intraperitoneal injection of CYP $(200 \mathrm{mg} / \mathrm{kg})$. TQ was administered intraperitoneally at 5,10 and $20 \mathrm{mg} / \mathrm{kg}$ doses twice a day, for three days before and three days after the CYP administration. The efficacy of TQ was determined in terms of the protection against the CYP-induced histological perturbations in the bladder tissue, reduction in the oxidative stress, and inhibition of the DNA fragmentation. Immunohistochemistry was performed to examine the expression of Nrf2. TQ protected against CYP-induced oxidative stress was evident from significant reduction in the lipid peroxidation, restoration of the levels of reduced glutathione, catalase and superoxide dismutase activities. TQ treatment significantly reduced the DNA damage evident as reduced DNA fragmentation. A significant decrease in the cellular infiltration, edema, epithelial denudation and hemorrhage were observed in the histological observations. There was restoration and rise in the $\mathrm{Nrf2}$ expression in the bladder tissues of mice treated with TQ. These results confirm that, TQ ameliorates the CYP-induced hemorrhagic cystitis in mice through reduction in the oxidative stress, inhibition of the DNA damage and through increased expression of Nrf2 in the bladder tissues.
\end{abstract}

Key words: Thymoquinone; cyclophosphamide; DNA damage; Nrf2; comet assay; cytokines

\section{Introduction}

Cyclophosphamide (CYP) remains the first line therapy in treatment of large granular lymphocyte leukaemia and metastatic breast cancer [1]. However, hemorrhagic cystitis is its dose limiting side effect 
implicating damage to the urothelium of the urinary bladder mucosa. CYP-induced cystitis leads to dysuria and gross hematuria and its repeated use over a period may lead to bladder cancer $[2,3]$. CYP is an inactive prodrug that gets metabolized to acrolein and phosphoramide. Acrolein increases the production of reactive oxygen species (ROS) including peroxynitrite which play a major role in the induction haemorrhagic cystitis and DNA damage [4, 5]. In the presence of reactive unsaturated aldehyde residues, acrolein cleaves the proteins and breaks the DNA strands leading to cell death [6]. It activates the formation of glutathionyl propionaldehyde (GTPD) from glutathione and thereby induces oxidative stress and generation of ROS in the urothelium [7]. The ROS including peroxinitrites are involved in DNA damage and depletion of the energy source of cells ultimately inducing cell death [6]. The subsequent destruction of urothelium further exposes the underlying smooth muscles and blood vessels to urine leading to further damages. A recent review on the methods for prevention of CYP-induced cystitis concludes that the cytokines, ROS, and modulation of transcription factors are involved in the pathogenesis of cystitis [4]. Mesna is widely used and is relatively successful in the treatment of CYP-induced cystitis. Still, there is a need of other drugs to selectively reduce the CYP-induced cystitis.

Thymoquinone (TQ), an active constituent of Nigella sativa seeds (Family: Ranunculaceae) is reported to reduce various chemical toxicities including CYP-induced pulmonary injury [8], cisplatin-induced hepatotoxicity and kidney injury $[9,10]$, and acetaminophen-induced hepatotoxicity [11]. TQ possesses potent antioxidant activity, induces phase-II antioxidant enzymes and reduces lipid peroxidation in different tissues. These effects correlate with the increased expression of nuclear factor related erythroid 2-related factor (Nrf2) and resultant induction of phase-II enzymes observed in experimental animals treated with TQ [12-14]. These effects are also observed in vitro in HaCaT cells co-incubated with TQ [15]. Induction of Nrf2 is involved in the protective effects of TQ against doxorubicin-induced nephrotoxicity in experimental animals and cytotoxicity against human leukocytes [16], [17].

In the light of these reports, the protective effect of TQ was evaluated against the CYP-induced hemorrhagic cystitis in mice. In this study, the antioxidant and DNA protective effects of TQ in the bladder tissue were determined by the DNA fragmentation assay and comet assay. Further, the effect of TQ on the expression of Nrf2 protein in the bladder sections was estimated by immunohistochemistry to determine the involvement of antioxidant and Nrf2- mediated effects of TQ against CYP-induced cystitis.

\section{Materials and Methods}

\section{Reagents and antibodies}

CYP (CAS No. 6055-19-2) procured from Cadila Healthcare Limited, B. No. BCP 1Q27), TQ (CAS No. 490-91-5) and 1,1,3,3-tetraethoxypropane were bought from Sigma-Aldrich, USA), RNase A (LOT No: 251014) (Merck, Bangalore), NBT (CAS No. 298-83-9) and 6X DNA (LOT No.0000207289) loading dye were obtained from Hi-media Laboratories Ltd., India., Nrf2 (C-20): sc-722 primary antibody (Lot number B1215), goat anti-rabbit IgG-FITC: sc-2012 secondary antibody (Lot numberG2314) and ImmunoCruz ${ }^{\mathrm{TM}}$ rabbit ABC Staining System: sc-2018 (Lot number L0114) were obtained from Santa Cruz Biotechnology, Inc., USA.

\section{Approval of the experimental protocols}

All animal experiment protocols were approved by the Institutional Animal Ethics Committee (Registration No. 651/02/C/CPCSEA; Protocol approval number IAEC/RCPIPER/2014-15/11). Thirty male Balb/c mice (18-25 g) were procured from the central animal house facility of the institute. The animals were placed in polypropylene cages, kept at room temperature $(25 \pm 2 \circ \mathrm{C})$, with $50 \pm 10 \%$ humidity along with a controlled $12 \mathrm{~h}$ light and $12 \mathrm{~h}$ dark cycle. Standard palletized feed (Amrut Feed, Pune, India) and tap water were provided ad libitum. Animals were acclimatized to the experimental conditions for a period of one week before the initiation of the experiment. All animals were maintained as per the standards prescribed by the Committee for the Purpose of Control and Supervision of Experiments on Animals (CPCSEA, Government of India).

\section{Dose selection and preparation of chemicals}

The dose of thymoquinone, body weight and intraperitoneal route for its administration was selected based on earlier studies [18-20]. Cyclophosphamide was diluted in saline $(0.9 \% \mathrm{NaCl})$ prior to injection and thymoquinone was freshly prepared in olive oil (Figaro, Spain) prior to administration [21, 22].

\section{Experimental design}

The study design and dosing schedule are represented in Figure 1. Cystitis was induced in mice by intraperitoneal administration of CYP at $200 \mathrm{mg} / \mathrm{kg}$. The detailed experimental schedule was described in fig. 1 . On day 1 , all the mice were administered with suspension of TQ $(5,10$ and 20 
$\mathrm{mg} / \mathrm{kg}$, i.p.) except the normal treated mice were administered with vehicle (Olive oil) for 3 consecutive days. On day 4, all the mice (except normal treated group) were administered with CYP $(200 \mathrm{mg} / \mathrm{kg}$, i.p.).From fifth day onwards, the mice were administered with TQ (5, 10 and $20 \mathrm{mg} / \mathrm{kg}$, i.p. respectively) for 3 consecutive days. On the eighth day, all the mice were sacrificed and the bladders were immediately isolated, weighed and processed for the histological and biochemical examination.

\section{Experimental parameters}

\section{Histological examination}

The bladder tissue was removed through a lower midline abdominal incision and stored in 10\% formalin solution. These specimens were split longitudinally and processed for histological examination using haematoxylin and eosin staining.

\section{Severity of inflammation}

The severity of CYP-induced inflammation was estimated in terms of mucosal abrasion, haemorrhage, leukocyte infiltration and oedema according to the protocol described by Ozcan et al., 2005 [11,23]. Mucosal abrasion was identified as erosion of the mucosa. The presence or absence of mucosal abrasion and haemorrhage was observed at 100x magnification. Leukocyte infiltration into the tissue bed and edema was determined at 400x magnification. The severity of the oedema was represent as absence of oedema (-),mild oedema with no alteration in the width of the submucosa $(+)$, moderate oedema with an increase of less than twice the width of the submucosa $(++)$ and $(+++)$ indicated severe oedema with an increase of more than twice the width of the submucosa [24].

\section{Estimation of DNA damage}

The bladder was isolated and the mucosa was scraped onto $1 \mathrm{ml}$ of chilled homogenizing buffer containing $0.075 \mathrm{M} \mathrm{NaCl}$ and $0.024 \mathrm{M} \mathrm{Na}_{2}$-EDTA. The content was homogenized at $500 \mathrm{rpm}$ followed by centrifuged at $700 \mathrm{~g}$ for $10 \mathrm{~min}$ at $0{ }^{\circ} \mathrm{C}$. The precipitate was re-suspended in chilled homogenized buffer to obtain cell suspension of $1 \times 10^{5} \mathrm{cells} / \mathrm{ml}$. From each sample $50 \mu \mathrm{l}$ of cell suspension was taken and added to $450 \mu \mathrm{l}$ of $1 \%$ low melting agarose. $100 \mu \mathrm{l}$ of this mixture was instilled as a second layer on the pre-coated $1 \%$ normal melting agarose $(120 \mu \mathrm{l})$ on the slide. A third layer of $100 \mu \mathrm{l}$ of $1 \%$ low melting agarose was made. Each time the agarose instillation was followed with placing of cover slip for obtaining uniform surface. These slides were placed on ice for 5-15 min for agarose solidification. The slides were then kept in chilled lysis solution containing $2.5 \mathrm{M}$ $\mathrm{NaCl}, 100$ mM Na 2 -EDTA, $10 \mathrm{mM}$ Tris, $\mathrm{NaOH}$, freshly prepared $1 \%$ triton X-100 and $10 \%$ DMSO (pH 10.0) at $0^{\circ} \mathrm{C}$ in dark for $3 \mathrm{hrs}$ followed by three washes with deionized water. Further, it was kept in chilled alkaline solution containing $300 \mathrm{mM} \mathrm{NaOH}$ and $1 \mathrm{mM}$ $\mathrm{Na}_{2}$-EDTA $\left(\mathrm{pH}\right.$ 13-14) for $10 \mathrm{~min}$ in dark at $0{ }^{\circ} \mathrm{C}$. Electrophoresis was conducted at $0{ }^{\circ} \mathrm{C}$ in the dark for $2 \mathrm{hr}$ at $50 \mathrm{~V}$ and $250 \mathrm{~mA}$ in the buffer containing $0.4 \mathrm{M}$ Tris (pH 7.4). Followed by electrophoresis the slides were stained with SYBR Green I solution [24,25].

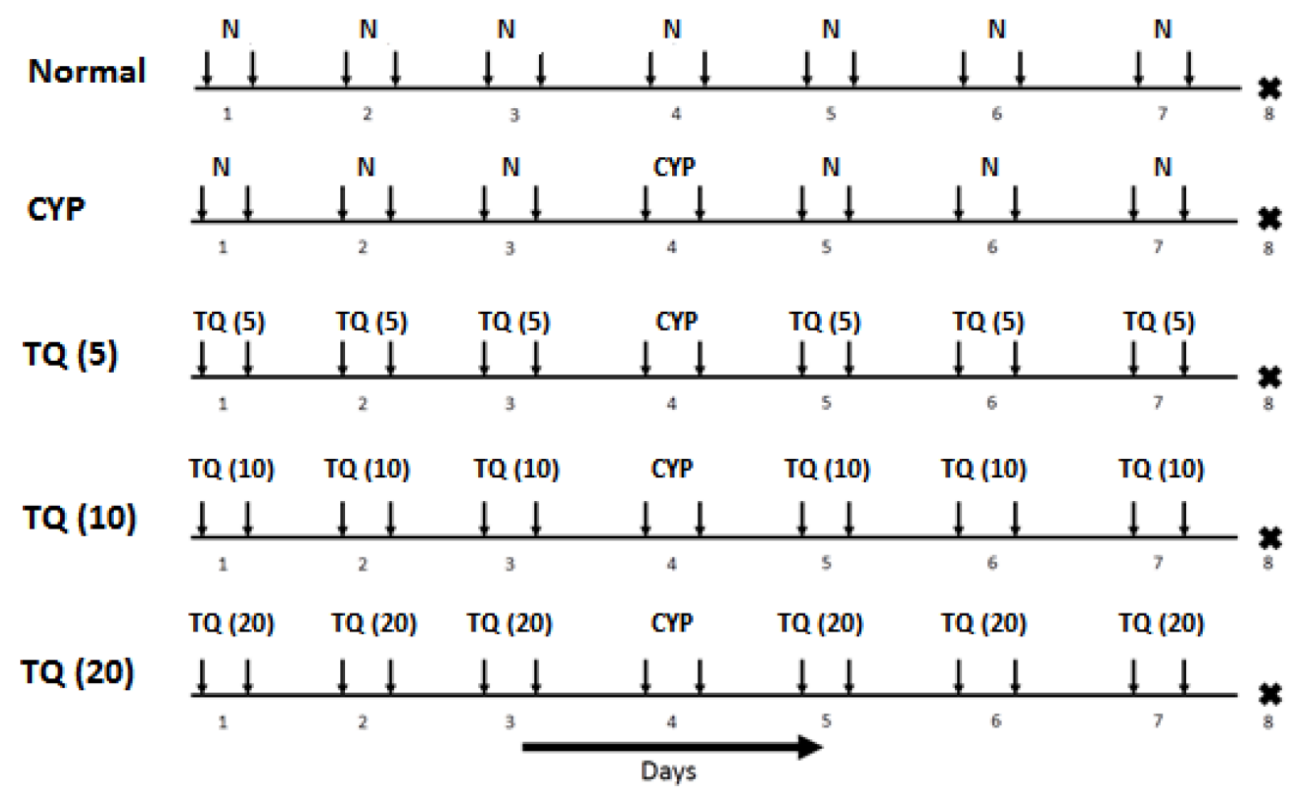

Figure 1. Experimental protocol for CYP-induced hemorrhagic cystitis in mice. Inverted arrows indicate the treatment schedule for particular day. The figures in the parenthesis indicates dose in mg/kg i.p. (N: Normal; CYP: Cyclophosphamide; TQ: Thymoquinone). 
The microscopic images of 50 randomly selected cells were obtained using fluorescent Motic microscope attached to a Moticam 1000 video camera equipped with excitation $(528 / 553 \mathrm{~nm})$ and barrier $(590 \mathrm{~nm})$ filters. The parameter used to determine the DNA damage was tail moment and \% DNA in tail and tail length. Tail length was determined as the distance of DNA migration from the nuclear core and was used to evaluate the extent of DNA damage. Tail moment was determined as a numerical measurement of DNA damage. It was calculated by multiplying the length of the "tail" of DNA trailing the nucleus and the percentage of total DNA content in the tail. An increase in the tail moment indicates increased DNA damage [26]. The comets (tail moment) were analyzed using CaspLab software version 1.2.3 (CASPLab, Wroclaw) software [27].

\section{Estimation of DNA fragmentation}

The DNA was isolated as per the protocol suggested by Tripathi and Jena [24], with slight modifications. The bladder tissue of equal weight was treated with cell lysis buffer $(2.5 \mathrm{M} \mathrm{NaCl}, 100 \mathrm{mM}$ $\mathrm{Na}_{2}$-EDTA, $10 \mathrm{mM}$ Tris, $\mathrm{NaOH}$, adjusted to $\mathrm{pH} 10$, freshly prepared $1 \%$ Triton X-100, followed by refrigeration at $4{ }^{\circ} \mathrm{C}$ for 60 minutes). After isolation, the DNA was re-suspended in $40 \mu \mathrm{l}$ tris-EDTA buffer. After overnight incubation at $4{ }^{\circ} \mathrm{C}$, RNase $\mathrm{A}$ was added and the mixture was incubated at $37{ }^{\circ} \mathrm{C}$ for 1 hour. The $10 \mu \mathrm{l}$ of the suspension was loaded into the wells with an equal amount of DNA loading dye. The gel was run at $50 \mathrm{~V}$, for $3 \mathrm{hrs}$ using $1 \%$ agarose gel. The obtained gel was observed in UV-365 nm on aetron gel documentation system instrument using electro-optical system (EOS) utility software, India.

\section{Estimation of $\mathrm{Nrf}-2$ expression by immunohistochemistry}

The paraffin-embedded sections of bladder were placed on poly-L-lysine coated slides. The sections were sequentially treated with $100 \%$ xylene, xylene: ethanol, $100 \%$ ethanol, $90 \%$ ethanol, $70 \%$ ethanol, 50 $\%$ ethanol in a graded manner. Each treatment lasted for 3 minutes. The slides were then placed in distilled water for 10 minutes followed by incubation with citrate buffer ( $\mathrm{pH} 6.0)$ at $95{ }^{\circ} \mathrm{C}$ for 5 minutes in water bath. Following this antigen retrieval the samples were cooled in citrate buffer for 20 minutes and washed thrice in deionized water followed by two washes in TBS for 5 minutes each. The specimens were then incubated for 1 hour in $1.5 \%$ normal blocking serum in TBS followed by addition of Nrf2 primary antibody (Santa Cruz Biotechnology, Inc., USA). The slides were maintained at $4^{\circ} \mathrm{C}$ overnight. Followed by antibody treatments the slides were rinsed twice in TBS containing $0.025 \%$ triton $\mathrm{X}-100$ incubated in $3 \% \mathrm{H}_{2} \mathrm{O}_{2}$ in TBS at room temperature for 15 minutes. The biotinylated secondary antibodies were added and the slides were incubated for 30 minutes and rinsed thrice with TBS. Following the addition of $\mathrm{AB}$ enzyme the slides were incubated for 30 minutes and then rinsed thrice with TBS. The slides were developed with $\mathrm{DAB}$ reagent and rinsed with distilled water for 5 minutes, dehydrated and the microscopic images were captured using Motic AE31 microscope attached to MXH-100 camera supported with Motic Images plus 2.0 software.

\section{Estimation of release of cytokines}

A $10 \%$ bladder homogenate was prepared in ice chilled phosphate buffer (50mM pH 7.4). The homogenate was centrifuged at $2000 \mathrm{~g}$ for $20 \mathrm{~min}$ at $4^{0}$ $\mathrm{C}$ and $100 \mu \mathrm{l}$ of the supernatant was used for the estimation of TNF- $\alpha$, IL-1 $\beta$ and IL- 6 using ELISA kits.

\section{Preparation of bladder homogenate for estimation of oxidative stress}

The bladder tissue was transferred to ice-cold phosphate buffered saline (pH 7.4) and cross-chopped with a surgical scalpel into fine slices, suspended in chilled $0.25 \mathrm{M}$ sucrose solution and quickly blotted on a filter paper. Tissues were minced and homogenized finally to release soluble proteins in ice cold tris hydrochloride buffer $(10 \mathrm{mM}, \mathrm{pH}$ 7.4). The homogenate so formed was centrifuged at $7000 \mathrm{rpm}$ for 20 minutes using high speed centrifuge and the supernatant was used for estimation of tissue parameters.

\section{Estimation of lipid peroxidation}

Lipid peroxidation in the bladder tissue was determined as MDA content by determining the thiobarbituric acid reactive substances[28]. Briefly, 0.2 $\mathrm{ml}$ of homogenate was mixed with $0.2 \mathrm{ml}$ of $8.1 \%$ sodium dodecyl sulphate, $1.5 \mathrm{ml}$ of $30 \%$ acetic acid ( $\mathrm{pH} 3.5)$ and $1.5 \mathrm{ml}$ of $0.8 \%$ thiobarbituric acid. The reaction mixture was heated for $60 \mathrm{~min}$ at $95{ }^{\circ} \mathrm{C}$ and cooled on ice bath. After cooling, $1.0 \mathrm{ml}$ of distilled water and $5.0 \mathrm{ml}$ of $\mathrm{n}$-butanol: pyridine $(15: 1 \mathrm{v} / \mathrm{v})$ solution was added to each tube and the tubes were centrifuged at $5000 \mathrm{rpm}$ for 20 minutes. The pink colored organic layer was separated and optical density was measured at $532 \mathrm{~nm}$. 1,1,3,3-tetraethoxypropane was used as a reference standard for MDA.

\section{Estimation of superoxide dismutase (SOD)}

To $100 \mu \mathrm{l}$ of tissue supernatant, $2.85 \mathrm{ml}$ of $0.1 \mathrm{M}$ phosphate buffer ( $\mathrm{pH} 8.4$ ) and $50 \mu \mathrm{l}$ of $7.5 \mathrm{mM}$ pyrogallol were added and optical density was measured at $420 \mathrm{~nm}$ for $3 \mathrm{~min}$ at $30 \mathrm{~s}$ intervals. 
Enzyme levels were expressed as SOD activity in units per mg protein[29].

\section{Estimation of Reduced glutathione (GSH)}

Briefly, $100 \mu \mathrm{l}$ of tissue homogenate was mixed with $100 \mu \mathrm{l}$ of $10 \%$ trichloro acetic acid and vortexed. The contents were then centrifuged at $5000 \mathrm{rpm}$ for 10 min. Subsequently $0.05 \mathrm{ml}$ of supernatant was mixed with a reaction mixture containing $3.0 \mathrm{ml} 0.3 \mathrm{M}$ phosphate buffer ( $\mathrm{pH} 8.4$ ) and $0.5 \mathrm{ml}$ DTNB [5, 5' dithiobis-(2-nitrobenzoic acid)]. Within $10 \mathrm{~min}$, the absorbance was measured at $412 \mathrm{~nm}$ using a spectrophotometer. GSH was determined from a standard curve produced using commercially available standard GSH (Sigma Chemicals, USA). The amount was expressed as $\mu \mathrm{g} / \mathrm{mg}$ of protein[30].

\section{Estimation of catalase}

For estimation of catalase activity, $50 \mu 1$ of tissue supernatant was taken and to it $1.0 \mathrm{ml}$ of $50 \mathrm{mM}$ phosphate buffer ( $\mathrm{pH} \mathrm{7}$ ) and $0.1 \mathrm{ml}$ of $30 \mathrm{mM}$ hydrogen peroxide were added. The decrease in absorbance at $240 \mathrm{~nm}$ was measured at $5^{\text {th }}$ and $30^{\text {th }}$ seconds. Catalase levels were expressed as units of catalase per mg protein $[31,32]$.

\section{Statistical analysis}

The statistical analysis was performed using Graph Pad Prism version 6.0 software, USA. The results were expressed as mean \pm S.E.M. The data sets of the experimental parameters were analysed using one-way analysis of variance (ANOVA) followed by
Dunnett's post-hoc test and $\mathrm{p}<0.05$ was considered to be statistically significant.

\section{Results}

\section{TQ inhibited CYP-induced perturbations in the bladder histopathology}

Light microscopic evaluation of the bladder sections revealed, CYP-treatment induced epithelial denudation, hemorrhage, nuclear infiltration and edema (black arrow) along with mild to moderate inflammatory exudates in the mucosa (white arrow). TQ dose dependently restored the bladder architecture and reduced CYP-induced inflammatory alternations. The mice treated with $10 \mathrm{mg} / \mathrm{kg}$ TQ had mild congestion in mucosa (black arrow) and no inflammatory exudates whereas, those receiving 20 $\mathrm{mg} / \mathrm{kg}$ TQ had mild congestion in the mucosa and complete protection of bladder tissues from CYP-induced inflammatory changes (Figure 2). The bladder histology of this group was similar to that observed in the normal mice (Table 1).

Table 1. Effect of TQ on urinary bladder histopathology in CYP-induced hemorrhagic cystitis

\begin{tabular}{lllll}
\hline Groups & $\begin{array}{l}\text { Epithelial } \\
\text { denudation }\end{array}$ & Hemorrhage & $\begin{array}{l}\text { Nuclear } \\
\text { infiltration }\end{array}$ & Edema \\
\hline Normal & - & - & - & - \\
CYP & +++ & +++ & +++ & +++ \\
TQ (5) & +++ & ++ & +++ & ++ \\
TQ (10) & + & + & ++ & + \\
TQ (20) & - & + & - & - \\
\hline
\end{tabular}

Severe (+++); Moderate (++); Mild (+); and Nil (-)

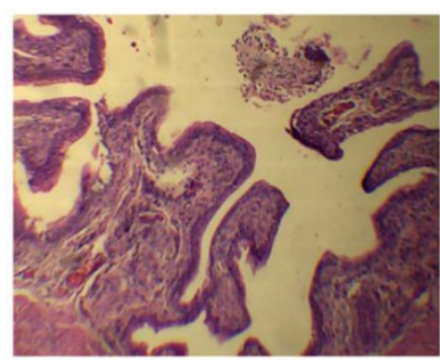

Normal

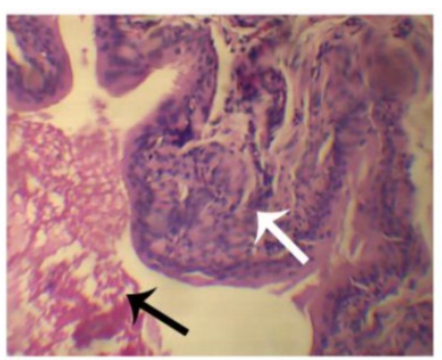

CYP

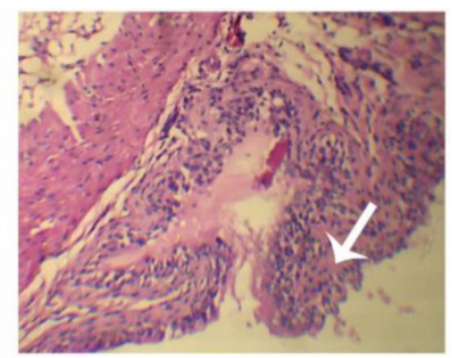

TQ (5 mg/kg)

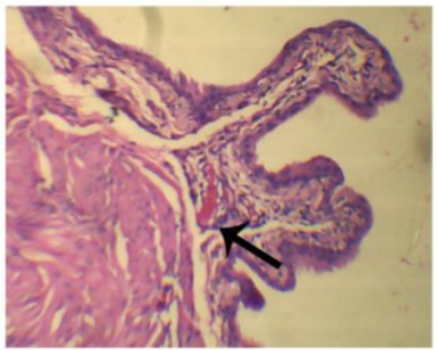

TQ $(10 \mathrm{mg} / \mathrm{kg})$

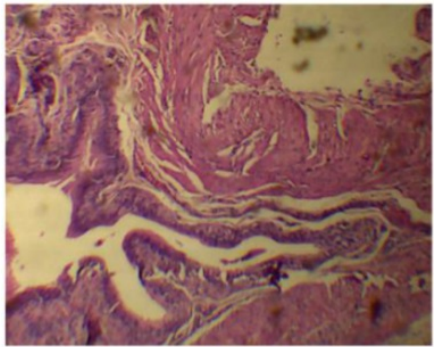

TQ $(20 \mathrm{mg} / \mathrm{kg})$

Figure 2. Effect of TQ on urinary bladder histopathology in CYP- induced hemorrhagic cystitis. Normal mice or control mice showed normal structure and architecture of bladder as compared to CYP treated group, Whereas mice treated with CYP showed increase in the nuclear infiltration, hemorrhage and edema, animals treated with TQ showed dose dependent mild edema and decrease the epithelial denudation as compared to CYP treated mice. The group treated with high dose of TQ showed higher improvements when compared with its low and medium dose (Scale bar: $20 \mu \mathrm{m})$. 
TQ reduced CYP-induced DNA fragmentation and in bladder epithelium

Agarose gel electrophoresis was conducted to analyze the pattern of the DNA fragmentation. CYP-treated mice showed significantly greater DNA fragmentation as apparent from the DNA ladder formation after electrophoresis of the genomic DNA. The genomic DNA samples isolated from bladders of mice treated with 5,10 and $20 \mathrm{mg} / \mathrm{kg}$ TQ had reduced DNA ladder formation indicating inhibition of DNA fragmentation (Figure 3). This effect was most prominent in the mice treated with $20 \mathrm{mg} / \mathrm{kg}$ dose of thymoquinone.

The extent of DNA damage was also assessed using various parameters derived through comet assay including tail moment, tail length and percent DNA content in the comet tail. The migration extent (tail length) of the DNA, besides, the percentage of DNA in the tail has been shown to be proportional to the frequency of DNA strand-breaks, and results might either be expressed by gathering cells into different damage categories according to the amount of DNA in the tail. Samples from CYP-treated mice had significantly higher percentage tail DNA content $(p<0.001)$, tail moment $(p<0.001)$ and tail length $(p<0.001)$ as compared the samples from the normal mice. The samples from mice treated with $20 \mathrm{mg} / \mathrm{kg}$ TQ had reduced percentage DNA in tail, tail moment and tail length $(p<0.001)$ respectively (figure 4$)$.

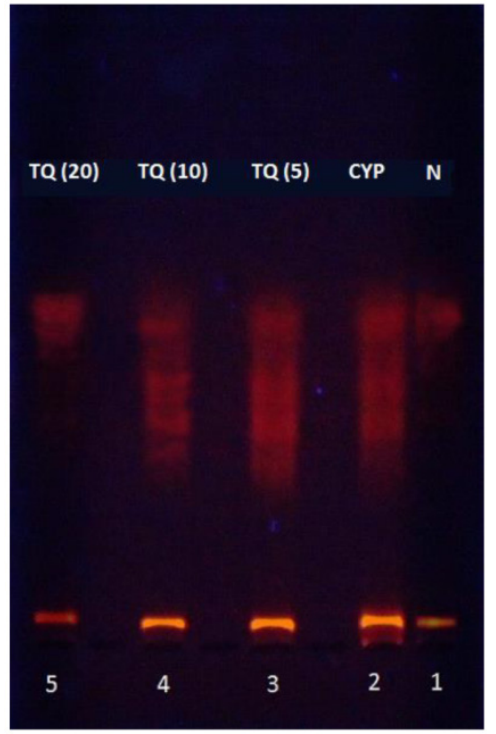

Figure 3. Effect of TQ on DNA damage in CYP-induced hemorrhagic cystitis. The figures in the parenthesis indicated dose in $\mathrm{mg} / \mathrm{kg}$ intraperitoneal N: Normal; CYP: Cyclophosphamide; TQ: Thymoquinone.

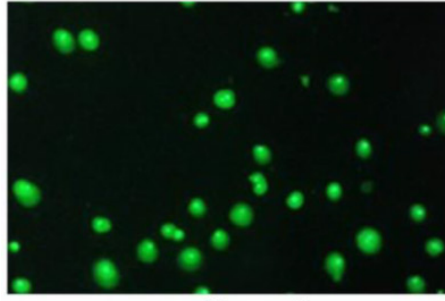

Normal

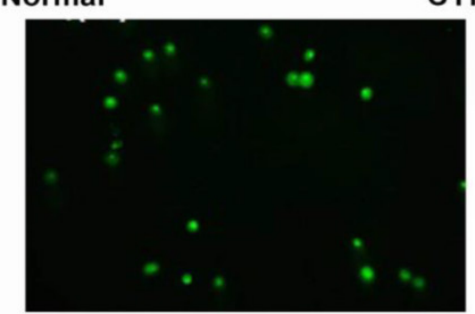

TQ (10 mg/kg)

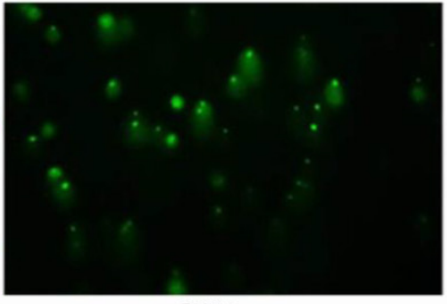

CYP

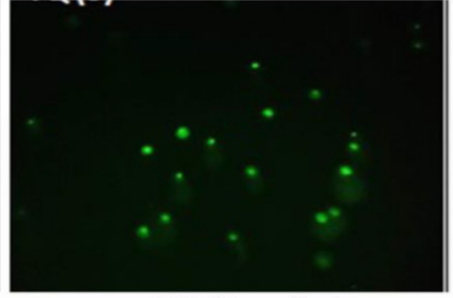

$\mathrm{TQ}(5 \mathrm{mg} / \mathrm{kg})$

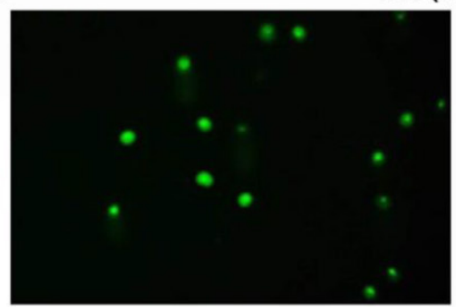

TQ (20 mg/kg)
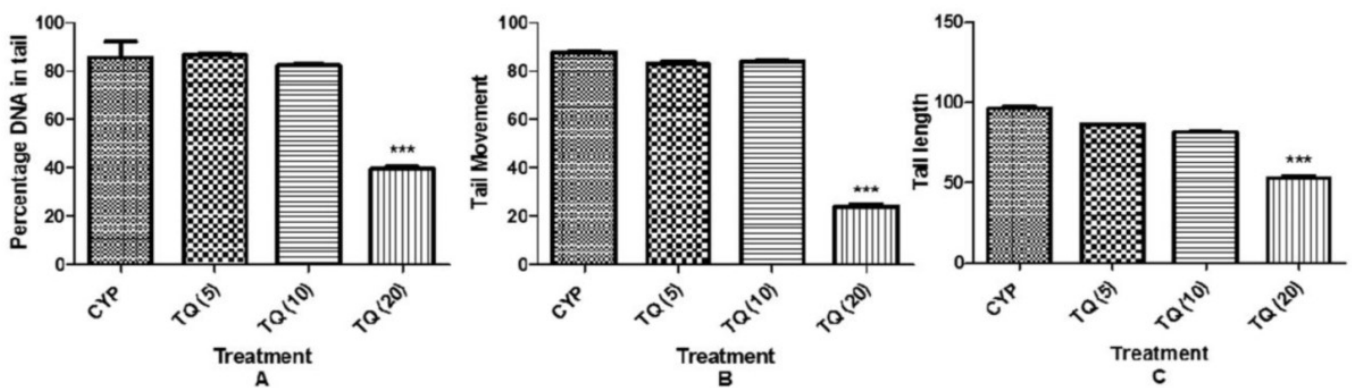

Figure 4. Effect of TQ on DNA damage in CYP- induced hemorrhagic cystitis. The pictures, obtained by fluorescence microscopy show identical comet fields with FITC (green). (CYP: Cyclophosphamide; TQ: Thymoquinone. Scale bar: $20 \mu \mathrm{m}$. (A) Percentage of DNA in tail; (B) Tail movement; (C) Tail length. Data is expressed as mean \pm SEM and analyzed by one way ANOVA followed by Dunnett's post hoc test. Figures in the parenthesis indicated dose in $\mathrm{mg} / \mathrm{kg}$ intraperitoneal. **** $<0.001$ as compared to CYP. (CYP: Cyclophosphamide; TQ: Thymoquinone) 


\section{Effect of TQ on expression of Nrf2 in CYP- induced hemorrhagic cystitis}

The protein expression of Nrf2 was estimated by immunohistochemistry as shown in Figure 5. The expression of Nrf2 decreases whenever there is an oxidative stress and bladder sections of CYP-treated rats had reduced Nrf2 expression. The TQ treatment reverted the Nrf2 suppression induced by CYP and most prominent expression of $\mathrm{Nrf} 2$ protein was evident in the group receiving $20 \mathrm{mg} / \mathrm{kg}$ of TQ.

\section{TQ reduced the CYP- induced release of inflammatory cytokines in bladder tissue}

To further define the mechanisms by which cytokine signaling may be associated with CYPinduced hemorrhagic cystitis, we examined the effect of TQ on release of pro-inflammatory cytokine expression of TNF- $\alpha$, IL-1 $\beta$ and IL- 6 in the tissue homogenate. The groups treated with CYP showed marked increase in the level of cytokines $(p<0.001)$ as compared to normal group, whereas treatment with the TQ showed decrease in the level of TNF- $\alpha$, IL-1 $\beta$ and IL- 6 in dose dependent manner indicating a consistent inhibitory effect on the cytokine release (Figure 6).

\section{TQ relives from oxidative stress in \\ CYP-induced hemorrhagic cystitis}

Oxidative stress eminence was evaluated by the measurement of MDA level as a marker of lipid peroxidation, GSH level as well as SOD activity and catalase activity as markers of enzymatic and non-enzymatic antioxidant defense systems. CYP induced a state of marked oxidative stress as demonstrated by significant increase $(p<0.001)$ in the MDA level and a significant decrease in the GSH level $(p<0.001)$, SOD $(p<0.001)$ and catalase $(p<0.001)$ activities in bladder tissue homogenates. Treatment with TQ alleviated the effect on the MDA and GSH levels, as well as SOD and catalase activities (figure 7).

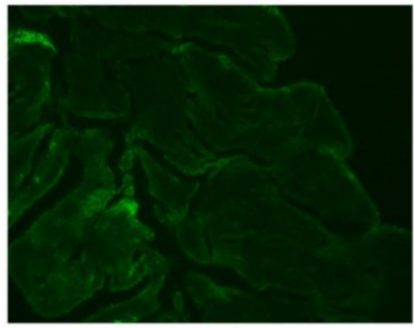

Normal

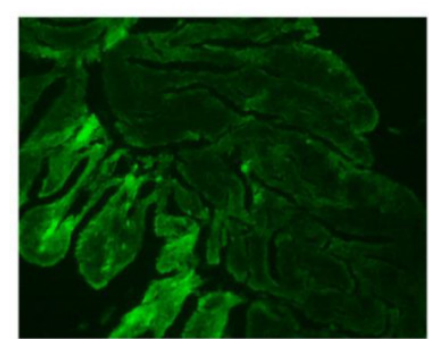

TQ $(10 \mathrm{mg} / \mathrm{kg})$

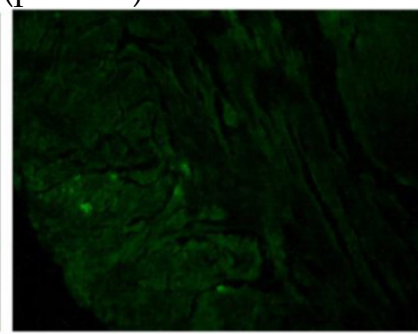

CYP

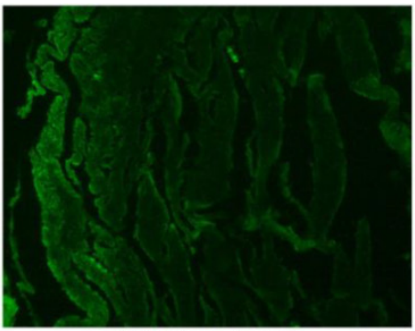

$\mathrm{TQ}(5 \mathrm{mg} / \mathrm{kg})$

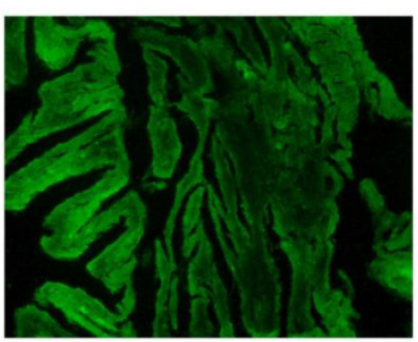

$\mathrm{TQ}(15 \mathrm{mg} / \mathrm{kg})$

Figure 5. Effect of TQ on Nrf2 expression in CYP-induced hemorrhagic cystitis. Altered expression patterns of nuclear factor 2-related factor (Nrf2) are observed in bladder tissue. Immunofluorescent microscopy revealed Nrf2 (green) is predominantly expressed in treatment with TQ in dose dependent manner as compared to CYP (Scale bar: $20 \mu \mathrm{m})$

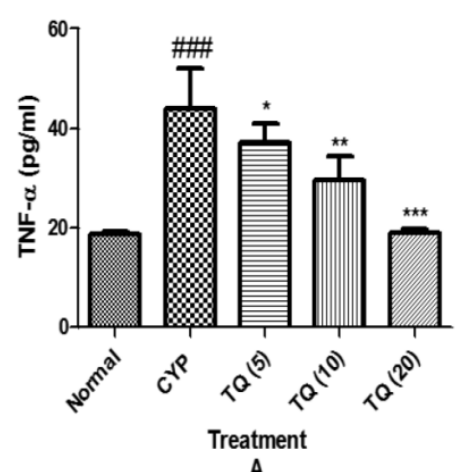

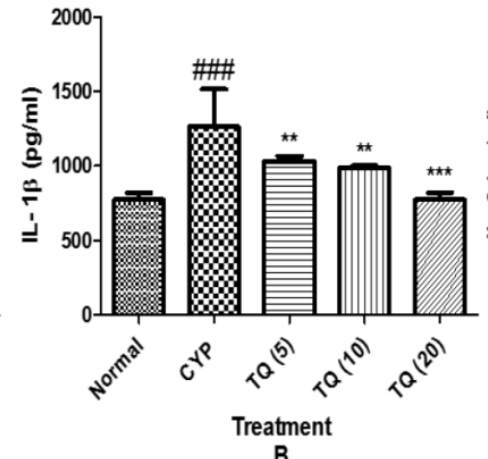

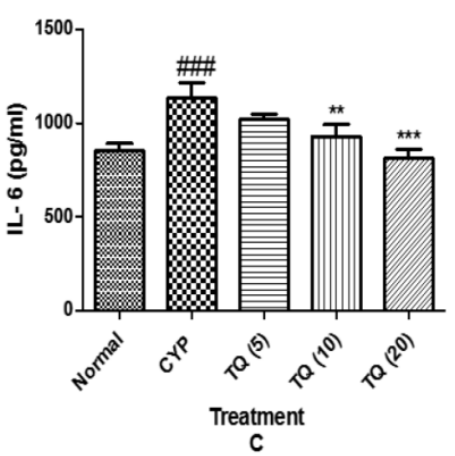

Figure 6. Effect of TQ on the release of pro-inflammatory cytokines in CYP- induced hemorrhagic cystitis. (A) Tumour necrosis factor- $\alpha$ (TNF- $\alpha$ ). (B) Interleukin-1 $\beta$ (IL-1 $\beta$ ) (C) Interleukin-6 (IL-6). Data is expressed as mean \pm SEM and analyzed by one way ANOVA followed by Dennett's post hoc test. Figures in the parenthesis indicated dose in $\mathrm{mg} / \mathrm{kg}$ intraperitoneal ${ }^{*} \mathrm{p}<0.05, *^{*} \mathrm{p}<0.01,{ }^{* * *} \mathrm{p}<0.001$ as compared to CYP and \#\# $\mathrm{p}<0.001$ as compared to normal $(\mathrm{CYP}$ : Cyclophosphamide; TQ: Thymoquinone). 

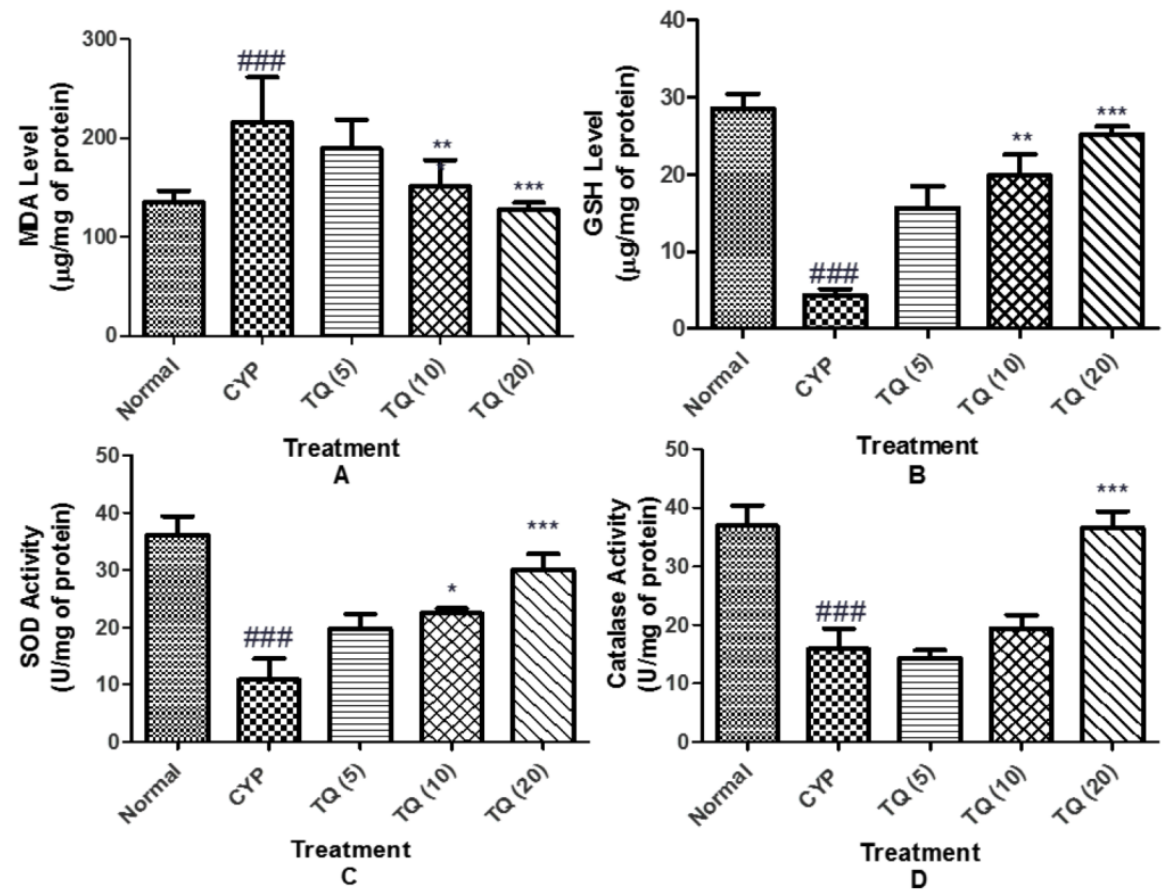

Figure 7. Effect of TQ on oxidative stress in CYP- induced hemorrhagic cystitis. (A) Malondialdehyde content (MDA); (B) Reduced glutathione (GSH); (C) Superoxide dismutase (SOD); (D) Catalase. Data is expressed as mean \pm SEM and analysed by one way ANOVA followed by Dunnett's post hoc test. Figures in the parenthesis indicated dose in $\mathrm{mg} / \mathrm{kg}$ intraperitoneal (CYP: Cyclophosphamide; TQ: Thymoquinone)

\section{Discussion}

The present study revealed that TQ exhibits a protective effect against CYP-induced hemorrhagic cystitis by improving organ function, restoring the endogenous antioxidant system, preventing the increased level of inflammatory cytokines such as TNF- $\alpha$ IL-1 $\beta$ and IL-6 \& DNA fragmentation; reducing lipid peroxide metabolism; and preserving the tissue structure and morphology of urinary bladder via activation of the Nrf2 signaling pathway. The present study shows for the first time that TQ exerts its organ-protective effects not only through its antioxidant effect but also in part by up regulating the Nrf2 pathway. Therefore, our study provides direct evidence that the Nrf2 signaling pathway plays a key role in regulating oxidative stress and subsequent CYP induced-injury in experimental animals. To the best of our knowledge, this is the first study to describe the protective effect of TQ against cyclophosphamide-induced hemorrhagic cystitis through inhibiting DNA damage and up regulating Nrf2 expression in mice.

The CYP-induced hemorrhagic cystitis in mice is used as an experimental model of the human diseases like urinary bladder inflammation, mastocyte infiltration, and urothelium disruption. This model represents the adverse effects of the toxic metabolites of CYP, phosphoramide and acrolein, which exert the cytotoxic effects on the rapidly dividing cells $[33,34]$.
These metabolites slow down the growth of cancer cells by interacting with the cellular DNA. Phosphoramide is mainly responsible for the mutagenic effect of CYP.

In present investigation the protective efficacy of twice a day intraperitoneal administration of TQ at 5, 10 and $20 \mathrm{mg} / \mathrm{kg}$ doses against CYP-induced cystitis was evaluated. The pharmacokinetics of TQ in rabbits is recently reported and there is a dearth of information on the pharmacokinetics of TQ in other species of experimental animals. We selected twice a day dose regimen for TQ administration considering that its elimination half-life in rabbits is $3.96 \pm$ 0.19 hours after extra vascular administration [35]. A preliminary investigations carried out in our laboratory on the protective effects of TQ at graded doses (5 to $40 \mathrm{mg} / \mathrm{kg}$, twice a day) revealed that TQ dose-dependently protected mice against CYP-induced alterations in the bladder histology. However, the $40 \mathrm{mg} / \mathrm{kg}$ dose appeared to induce more inflammatory damage of the bladder tissue. Hence, in the main study TQ was tested at 5, 10 and 20 $\mathrm{mg} / \mathrm{kg}$ b.i.d doses. Similar doses for evaluating chemopreventive effect of TQ against cisplatin toxicity have been evaluated [36].

It is well documented that CYP-induced cystitis involves increased in oxidative stress and inflammation. The characteristic histological perturbations related CYP-induced cystitis like epithelial denudation, hemorrhage; cellular 
infiltration and edema were observed in present study. It is well reported that TQ has multi-organ protection activities against chemically induced nephrotoxicity [37] and cardiotoxicity [38]. In present study, TQ dose-dependently inhibited the release of inflammatory cytokines including IL-1, IL-6 and TNF-a. This cytokine inhibitory effect of TQ might has contributed to the protection of bladder architecture and reduced inflammatory infiltration in the bladder tissue. The role of TNF-a in CYP-induced cystitis has been established[39]. Therefore, the organ protection activity might be due to inhibition of proinflammatory cytokines in CYP-induced cystitis.

CYP possesses pro-oxidant nature and induces oxidative stress through decreasing the activities of the antioxidant enzymes. It increases the extent of the lipid peroxidation [40]. In the present study, CYP treatment significantly increased the MDA levels in the bladder homogenate indicating enhanced lipid peroxidation. A decrease in the GSH levels and activities of catalase and SOD were also observed in CYP treated mice. A reduction in the GSH content may be attributed to the direct conjugation of CYP metabolites with the free or protein bound $-\mathrm{SH}$ groups. The pro-inflammatory component of the CYP-toxicity may also contribute to the disturbance of overall redox cycling in the bladder tissues [24]. It was observed that the TQ treatment significantly reduced the extent of lipid peroxidation and improved the levels of GSH and activities of SOD and CAT.

Nrf2-mediated cytoprotection has been shown to be critical for the tissues that are vulnerable to oxidative stress. Therefore, Nrf2 is recognized as an important molecular target for a number of chemopreventive and cytoprotective agents [19]. In present study, treatment of mice with CYP led to a reduction in Nrf2 protein expression and subsequent rise in the oxidative stress. This action is due to CYP metabolites that suppress the activity of Nrf2 and inhibit phase II antioxidant enzymes leading to increased oxidative stress and tissue damage. In current study, we observed that Nrf2 expression was significantly increased after TQ treatment. Recently, TQ is reported to induce phase-II enzymes involved in the antioxidant activities through activation of the Nrf2 pathway [15]. Also, TQ has been reported to enhance the level of Nrf2 expression and increase the expression of genes involved in the recognition and repair of damaged DNA/fragmented DNA. This effect could provide secondary protection against DNA damage that enhances the cell survival [41]. TQ is a strong antioxidant and its indirect antioxidant action is mediated through the activation of transcription factor Nrf2 protein in the bladder tissue. The role of oxidative and nitrosative stress in the
CYP-induced bladder damage is reported earlier 2007 [42]. It is suggested that TQ might induce the phase-II enzymes NQO-1 and HO-1. However, further investigation is warranted to confirm such induction of the phase-II enzymes.

Increase in oxidative stress may lead to damage to DNA as observed by comet and modified comet assay parameters according to the experiment conducted by Tripathi and Jena [24]. The DNA fragmentation assay for the estimation of DNA damage in mammalian cells has several advantages over other cytogenetic bio-assays [43]. Treatment of mice with CYP significantly increased the DNA damage in the bladder cells. This was evident from the increased tail movement and increased tail DNA content as observed in the comet assay. These results indicate that the TQ treatment protects against the CYP-induced DNA damage. Moreover, the DNA damage analysis using DNA ladder assay reveals increased fragmentation and formation of low molecular weight DNA bands in the CYP treated animal samples. Fragmentation in DNA leads to apoptosis of the cell and produced the internal toxicity leads to cell death [44]. Treatment with the TQ dose dependently provides the protection against CYP-induced DNA fragmentation. This effect can be attributed to the earlier reported free radical scavenging and anti-apoptotic activity of TQ [14, 45].

\section{Conclusion}

Thus, we conclude that the TQ reduces oxidative stress, inflammatory cytokines and DNA fragmentation in CYP-induced cystitis via the Nrf2 pathway. Future investigation targeting molecular pathways involved in the protective action of TQ on CYP-induced cystitis are warranted to confirm the role of TQ in CYP-induced cystitis.

\section{Abbreviations}

CYP: Cyclophosphamide; TQ: Thymoquinone; Nrf2: Nuclear factor erythroid 2-related factor 2; ROS: Reactive oxygen species; NF-кB: nuclear factor- $\mathrm{\kappa B}$; GTPD: Glutathionyl propionaldehyde; HO1: hemooxugenase-1; NBT: Nitro blue tetrazolium; FITC: Fluoroisothyocynate; EOS: electro-optical-system; NQO-1: NADH quinone oxidoreductase 1.

\section{Acknowledgments}

The authors acknowledge the financial support to the research works in the laboratory of Dr. Shreesh Ojha from United Arab Emirates University, United Arab Emirates. 


\section{Competing Interests}

The authors have declared that no competing interest exists.

\section{References}

1. Moignet A, Hasanali Z, Zambello R, Pavan L, Bareau B, Tournilhac O, et al. Cyclophosphamide as a first-line therapy in LGL leukemia. Leukemia. 2014; 28: 1134-6.

2. Monach PA, Arnold LM, Merkel PA. Incidence and prevention of bladder toxicity from cyclophosphamide in the treatment of rheumatic diseases: A data-driven review. Arthritis Rheumatism. 2010; 62: 9-21.

3. Travis LB, Curtis RE, Glimelius B, Holowaty EJ, Van Leeuwen FE, Lynch CF, et al. Bladder and kidney cancer following cyclophosphamide therapy for non-Hodgkin's lymphoma. Journal of the National Cancer Institute. 1995; 87: 524-31.

4. Emadi A, Jones RJ, Brodsky RA. Cyclophosphamide and cancer: golden anniversary. Nat Rev Clin Oncol. 2009; 6: 638-47.

5. Korkmaz A, Topal T, Oter S. Pathophysiological aspects of cyclophosphamide and ifosfamide induced hemorrhagic cystitis; implication of reactive oxygen and nitrogen species as well as PARP activation. Cell Biol Toxicol. 2007; 23 : 303-12.

6. Beckman JS, Koppenol WH. Nitric oxide, superoxide, and peroxynitrite: the good, the bad, and ugly. Am J Physiol Cell Physiol. 1996; 271: C1424-C37.

7. Gomes T, Santos C, Souza-Filho M, Cunha F, Ribeiro R. Participation of TNF-alpha and IL-1 in the pathogenesis of cyclophosphamide-induced hemorrhagic cystitis. Brazil J Med Biol Res. 1995; 28: 1103-8.

8. Suddek GM, Ashry NA, Gameil NM. Thymoquinone attenuates cyclophosphamide-induced pulmonary injury in rats. Inflammopharmacol. 2013; 21: 427-35.

9. Al-Malki AL, Sayed AAR. Thymoquinone attenuates cisplatin-induced hepatotoxicity via nuclear factor kappa- $\beta$. BMC Complement Altern Med. 2014; 14: 282.

10. Ulu R, Dogukan A, Tuzcu M, Gencoglu H, Ulas M, İlhan N, et al. Regulation of renal organic anion and cation transporters by thymoquinone in cisplatin induced kidney injury. Food Chem Toxicol. 2012; 50: 1675-9.

11. Aycan IO, Tufek A, Tokgoz O, Evliyaoglu O, Firat U, Kavak GO, et al. Thymoquinone treatment against acetaminophen-induced hepatotoxicity in rats. Int J Surg. 2014; 12: 213-8.

12. Giudice A, Arra C, Turco MC. Review of molecular mechanisms involved in the activation of the Nrf2-ARE signaling pathway by chemopreventive agents. Transcription Factors: Meth Prot. 2010: 37-74

13. Kamble SM, Goyal SN, Patil CR. Multifunctional pentacyclic triterpenoids as adjuvants in cancer chemotherapy: a review. RSC Advances. 2014; 4: 33370-82.

14. Ma Q. Role of nrf2 in oxidative stress and toxicity. Annu Rev Pharmacol Toxicol. 2013; 53: 401.

15. Kundu J, Kim D-H, Kundu JK, Chun K-S. Thymoquinone induces heme oxygenase-1 expression in HaCaT cells via Nrf2/ARE activation: Akt and AMPKa as upstream targets. Food Chem Toxicol. 2014; 65: 18-26.

16. Elsherbiny NM, El-Sherbiny M. Thymoquinone attenuates Doxorubicin-induced nephrotoxicity in rats: Role of Nrf2 and NOX4. Chem Biol Interact. 2014; 223: 102-8

17. Al-Shdefat RI, Abd-ElAziz MA, Al-Saikhan FI. Genoprotective and Genotoxic Effects of Thymoquinone on Doxorubicin-Induced Damage in Isolated Human Leukocytes. Trop J Pharma Res. 2015; 13.

18. Al-Ali A, Alkhawajah AA, Randhawa MA, Shaikh NA. Oral and intraperitoneal LD50 of thymoquinone, an active principle of Nigella sativa, in mice and rats. J Ayub Med Coll Abbottabad. 2008; 20: 25-7.

19. Badary OA, Al-Shabanah OA, Nagi MN, Al-Bekairi AM, Elmazar M. Acute and subchronic toxicity of thymoquinone in mice. Drug Dev Res. 1998; 44: 56-61.

20. Mahmoud AM, Ahmed OM, Galaly SR. Thymoquinone and curcumin attenuate gentamicin-induced renal oxidative stress, inflammation and apoptosis in rats. EXCLI J. 2014; 13: 98.

21. El-Naggar SA, Alm-Eldeen AA, Germoush MO, El-Boray KF, Elgebaly HA. Ameliorative effect of propolis against cyclophosphamide-induced toxicity in mice. Pharm Biol. 2015; 53: 235-41.

22. Shokrzadeh M, Ahmadi A, Naghshvar F, Chabra A, Jafarinejhad M. Prophylactic efficacy of melatonin on cyclophosphamide-induced liver toxicity in mice. BioMed Res Int. 2014; 2014.

23. Ozcan A Korkmaz A Oter $\mathrm{S}$, Coskun O Contribution of flavonoid antioxidants to the preventive effect of mesna in cyclophosphamide-induced cystitis in rats. Arch Toxicol. 2005; 79: 461-5.

24. Tripathi D, Jena G. Astaxanthin intervention ameliorates cyclophosphamide-induced oxidative stress, DNA damage and early hepatocarcinogenesis in rat: role of Nrf2, p53, p38 and phase-II enzymes. Mut Res/Gen Toxicol Envl Mutagen. 2010; 696: 69-80.

25. Sasaki YF, Kawaguchi S, Kamaya A, Ohshita M, Kabasawa K, Iwama K, et al. The comet assay with 8 mouse organs: results with 39 currently used food additives. Mut Res/Gen Toxicol Envl Mutagen. 2002; 519: 103-19.
26. Ferreira $\mathrm{S}$, Peliciari-Garcia $\mathrm{R}$, Takahashi-Hyodo $\mathrm{S}$, Rodrigues A, Amaral $\mathrm{F}$, Berra $C$, et al. Effects of melatonin on DNA damage induced by cyclophosphamide in rats. Brazil J Med Biol Res. 2013; 46: 278-86.

27. Konca K, Lankoff A, Banasik A, Lisowska H, Kuszewski T, Gozdz S, et al. A cross-platform public domain PC image-analysis program for the comet assay. Mut Res/Gen Toxicol Envl Mutagen. 2003; 534: 15-20.

28. Oyagbemi AA, Omobowale OT, Asenuga ER, Akinleye AS, Ogunsanwo RO, Saba AB. Cyclophosphamide-induced hepatotoxicity in wistar rats: The modulatory role of gallic acid as a hepatoprotective and chemopreventive phytochemical. Int J Prev Med. 2016;7: 51.

29. Quita SM, Al Amri WS. Study of the possible protective effect of lemon fruit extract against the histopathological changes induced in kidney of male mice treated with cyclophosphamide. J Am Sci. 2015;11(12): 30-38

30. Sherif IO, Nakshabandi ZM, Mohamed MA, Sarhan OM. Uroprotective effect of oleuropein in a rat model of hemorrhagic cystitis. Int J Biochem cell Biol. 2016 May 31;74:12-7.

31. Zhang X, Yao J, Gao K, Chi Y, Mitsui T, Ihara T, Sawada N, Kamiyama M, Fan J, Takeda M. AMPK Suppresses Connexin43 Expression in the Bladder and Ameliorates Voiding Dysfunction in Cyclophosphamide-induced Mouse Cystitis. Sci Rep. 2016;6:19708

32. Reddy NM, Mahajan UB, Patil CR, Agrawal YO, Ojha S, Goyal SN. Eplerenone attenuates cardiac dysfunction and oxidative stress in $\beta$-receptor stimulated myocardial infarcted rats. Am J Trans Res. 2015;7(9):1602-1611.

33. Cannon J, Links CA, Cos LR. Cyclophosphamide-associated carcinomaof urothelium: Modalities for prevention. Urol. 1991; 38: 413-6.

34. Choi SH, Byun Y, Lee G. Expressions of uroplakins in the mouse urinary bladder with cyclophosphamide-induced cystitis. J Korean Med Sci. 2009; 24: 684-9.

35. Abdelwahab SI, Sheikh BY, Taha MME, How CW, Abdullah R, Yagoub U, et al. Thymoquinone-loaded nanostructured lipid carriers: preparation, gastroprotection, in vitro toxicity, and pharmacokinetic properties after extravascular administration. Int J Nanomed. 2013; 8: 2163-72.

36. Sagit M, Korkmaz F, Akcadag A, Somdas MA. Protective effect of thymoquinone against cisplatin-induced ototoxicity. European Archives of Oto-Rhino-Laryngology. 2013; 270: 2231-7.

37. El-Sheikh AA, Morsy MA, Abdalla AM, Hamouda AH, Alhaider IA. Mechanisms of Thymoquinone Hepatorenal Protection in Methotrexate-Induced Toxicity in Rats. Med Inflam. 2015; 2015.

38. Gonca E, Kurt Ç. Cardioprotective effect of Thymoquinone: A constituent of Nigella sativa L., against myocardial ischemia/reperfusion injury and ventricular arrhythmias in anaesthetized rats. Pak J Pharm Sci. 2015; 1: 1267-73

39. Malley SE, Vizzard MA. Changes in urinary bladder cytokine mRNA and protein after cyclophosphamide-induced cystitis. Physiol Genom. 2002; 9: 5-13.

40. Haque R, Bin-Hafeez B, Parvez S, Pandey S, Sayeed I, Ali M, et al. Aqueous extract of walnut (Juglans regia L.) protects mice against cyclophosphamideinduced biochemical toxicity. Human Exp Toxicol. 2003; 22: 473-80.

41. Zhou F, Wu JY, Sun XL, Yao HH, Ding JH, Hu G. Iptakalim alleviates rotenone-induced degeneration of dopaminergic neurons through inhibiting microglia-mediated neuroinflammation. Neuropsychopharmacol. 2007; 32: 2570-80.

42. Linares-Fernández BE, Alfieri AB. Cyclophosphamide Induced Cystitis: Role of Nitric Oxide Synthase, Cyclooxygenase-1 and 2, and NK 1 Receptors. J Urol. 2007; 177: 1531-6.

43. Kumar PV, Seshadri M, Jaikrishan G, Das B. Effect of chronic low dose natural radiation in human peripheral blood mononuclear cells: Evaluation of DNA damage and repair using the alkaline comet assay. Mutat Res Fund Mol Mech Mut. 2015; 775: 59-65

44. El-Ghany R, Sharaf N, Kassem L, Mahran L, Heikal O. Thymoquinone triggers anti-apoptotic signaling targeting death ligand and apoptotic regulators in a model of hepatic ischemia reperfusion injury. Drug Discov Ther. 2009; 3: 296-306.

45. Huang Y, Li W, Su Z-y, Kong A-NT. The complexity of the Nrf2 pathway: beyond the antioxidant response. J Nutr Biochem. 2015; 26: 1401-13. 